\title{
Influence of physical activity of the maximum aerobic power on hemo-dynamic and morpho-biochemical of change of erythrocytes of female volleyball players
}

\author{
Mytckan B. M. ${ }^{1 \mathrm{ABCDE}}$, Verbovyi V. P. ${ }^{2 \mathrm{AC}}$, Chovhan R. Ya. ${ }^{3 \mathrm{BC}}$, Zemska N. O. ${ }^{4 \mathrm{BC}}$, Kryzanivskaya O.F. ${ }^{3 \mathrm{BC}}$, Bublyk S. \\ A. ${ }^{3 \mathrm{BC}}$, Mocherniuk V. B. ${ }^{1 \mathrm{ABC}}$, Faichak R. I. ${ }^{\mathrm{B} C \mathrm{CE}}$, Pjatnichuk G.O. ${ }^{4 \mathrm{BC}}$, Popel' S. L. ${ }^{1 \mathrm{ABCDE}}$, Baskevich O. V. ${ }^{5 \mathrm{ACE}}$ \\ ${ }^{1}$ Department of Theory and Methodology of Physical Culture and Sports, Vasyl Stefanyk Precarpathian National \\ University, Ukraine \\ ${ }^{2}$ Department of Tactical-Special, Physical and Fire Training, National Academy of Internal Affairs, Ukraine \\ ${ }^{3}$ Department of Physical Culture, Vasyl Stefanyk Precarpathian National University, Ukraine \\ ${ }^{4}$ Department of Sport-Pedagogical Subject Matters, Vasyl Stefanyk Precarpathian National University, Ukraine \\ ${ }^{5}$ Department of Physical Rehabilitation, Vasyl Stefanyk Precarpathian National University, Ukraine
}

Authors' Contribution: A - Study design; B - Data collection; C - Statistical analysis; D - Manuscript Preparation; E - Funds Collection.

\begin{abstract}
Purpose:

to study types of the cardio-hemo-dynamic reaction of an organism and morpho-biochemical changes of erythrocytes of peripheral blood of female volleyball players on physical activity of the maximum aerobic power.

Material: $\quad 18$ female volleyball players with different qualification participated in the experiment (age $-22,0 \pm 0,6$ years). It is investigated cardio-hemo-dynamic (by functional methods), functional changes (by biochemical methods) and structure of erythrocytes (by means of the scanning electronic microscopy) before and after maximum (3,5 W/kg of body mass) physical activity.

Results: It is determined that the maximum physical activity causes essential changes in cardio-hemo-dynamic. Such changes depend on the morphological reorganization of peripheral blood erythrocytes (increase in the index of erythrocytes deformation) and closely correlate with biochemical changes (decrease of ATP concentration and increase of magnesium concentration in erythrocytes). It is discussed the possible mechanisms of realization of reaction features of the organism of female volleyball players to physical activity of the maximum aerobic power.

Conclusions: the physical activity of the maximum aerobic power finds typological features of the cardio-hemo-dynamic reaction of the female volleyball players' organism. Such features are expressed by conformational changes of erythrocytes of peripheral blood. They depend on the concentration of separate macroelements in these cells and type of cardio-hemo-dynamic.

Keywords: female volleyball players, blood circulation type, macroelements, physical activity, erythrocytes.
\end{abstract}

\section{Introduction}

The defining parameter of different types of cardiohemo-dynamic is the heart index [1]. Definition of this parameter promoted identification of functionality stocks of students [2] and athletes' organism of different age groups [4]. The longtime jogging also promoted the selection of males and females training tactics [3]. Its fluctuations range in healthy humans is devoted to several types of cardio-hemo-dynamic [1]. At the same time, such heterogeneity is caused by the level of vegetative regulation [4] and is the standard of somatic health of different age human [5] and students of different gender [6].

Physical activity of the maximum aerobic power could cause changes in the central cardio-hemo-dynamic [4]. It creates prerequisites for violation of an erythrocytic part of hemostasis [7]. Such changes of erythrocytes are defined by biochemical and macroelement imbalance which

(c) Mytckan B. M., Verbovyi V. P., Chovhan R. Ya., Zemska N. O., Kryzanivskaya O.F., Bublyk S. A., Mocherniuk V. B.,

Faichak R. I., Pjatnichuk G.O., Popel' S. L.,

Baskevich O. V., 2018

doi:10.15561/18189172.2018.0508 influences on their deformability [8]. The intracellular concentration of ions of magnesium and calcium [7] is important among determination factors of erythrocytes deformation ability. It is known that the interaction of 2,3-diphosphoglycerate and adenosine triphosphoric acid (ATP) with hemoglobin is substantially regulated by these ions. It is also known that magnesium contacts with a molecule of 2,3-diphosphoglycerate. It increases the ability of hemoglobin to keep intracellular oxygen [9]. At the same time, the quantity of intracellular ions of magnesium and calcium creates the significant effect on the cardio-hemo-dynamic level [3]. This fact substantially depends on the type of vegetative regulation of the heart rhythm [10].

There are only several works devoted to a research of types of hemo-dynamic depending on the morphobiochemical condition of erythrocytes [4]. At the same time, there is no clearness in what ratio of such types meet at healthy humans [11]. Data of several authors indicate identical part of different types of cardio-hemodynamic [1]. In other researches advantage of one of them is determined [12] that also depends on a person's age [13] and gender [14]. At the same time out the questions 
of their origin are neglected [11]. It isn't found features of such reaction to physical activity of the maximum aerobic power $[15,16]$ in athletes: depending on their age [5], gender[16] and specialization [15].

Hypothesis. It is provided that athletes with the different type of cardio-hemo-dynamic reaction to physical activity of the maximum aerobic power could be caused by changes of macroelements' structure and erythrocytes deformation ability.

The work purpose is to study the features of cardiohemo-dynamic reaction of female volleyball players' organism to physical activity of the maximum aerobic power depending on morpho-biochemical features of peripheral blood erythrocytes.

\section{Material and methods.}

Participants. Female volleyball players $(\mathrm{n}=18$, age $20,0 \pm 0,6$ years) who gave the letter of consent participated in a research.

Organization of a research. The physical activity of the maximum aerobic power of $3,5 \mathrm{~W} / \mathrm{kg}$ of body mass was applied during the research. The test was performed on the bicycle ergometer Kettler (Germany). Definition of cardio-hemo-dynamic parameters performed by means of the computer cardiographic complex Cardiolab+ (XAIMedica, Ukraine).

Cardio-hemo-dynamic changes were estimated according to the following parameters: heart index; systolic blood pressure, diastolic blood pressure, and average arterial blood pressure; changes of heart rate; stroke and minute volume of blood circulation. The power characteristics of heart activity [10] and myocardial oxygen requirement [17] were defined according to the rate pressure product value.

The capillary blood sampling was done for studying of morpho-biochemical changes of erythrocytes. It was determined glucose level in blood plasma before and after 5 minutes of physical activity of the maximum aerobic power. The concentration of hemoglobin was investigated by a standard cyanmethemoglobin method [14]. The number of erythrocytes was determined by the unified method in Gorjaev's chamber [18]. Hematocrit was determined by micromethod with the application of standard heparinized capillaries [19]. The concentration of adenosine triphosphate (ATP) in erythrocytes was defined by means of P.M. Yaverbaum's method [8]. The concentration of adenosine diphosphate (ADP) and adenosine monophosphate (AMP) were defined by means of Bergmeyer's method [8].

Morphological researches of erythrocytes were performed in the scanning electronic microscope "JEOL25M-T220A" (Japan) [20].

The erythrocytes deformation index was calculated by the formula for the comparison of different forms of erythrocytes and assessment of their morphological comfortability level:

$$
\mathrm{EDI}=\mathrm{A}-\mathrm{B} / \mathrm{C} \text {, }
$$

where A - total quantity of erythrocytes, B - quantity of reversibly changed forms of erythrocytes, $\mathrm{C}$ - quantity of irreversibly changed forms of erythrocytes. Low level of conformational ability of erythrocytes is defined at values of the erythrocytes deformation index from 1,6 to 2,5 , average - within 2,6-3,9, high - at 4,0-6,0.

The electrolytic structure of erythrocytes was defined in the muffle furnace at $800 \mathrm{Co} \mathrm{t}$. For this purpose, $2 \mathrm{ml}$ of erythrocytic mass was turned into ash. Ash was pressed after then the surface of press mould was sputtering by carbon $(\approx 10 \mathrm{~nm})$. It was defined concentration in erythrocytes of such macroelements as following: sodium $(\mathrm{Na})$, potassium $(\mathrm{K})$, iron $(\mathrm{Fe})$, magnesium $(\mathrm{Mg})$ and calcium (Ca). The computer program "SELMI" was applied for this purpose. Accessory for energy dispersive X-ray microanalysis "EDAR" was also applied. Raster electronic microscope REMMA-102E ("SELMI", Ukraine) was applied for this purpose: accelerating voltage - $20 \mathrm{~kW}$; power range from 960 to 19600 kiloelectron-volt (keW).

Statistical analysis. Statistical processing is performed by means of computer software "Statistica 6,0 ". Data are presented in the arithmetic average, the standard deviation is $(\mathrm{M} \pm \mathrm{SD})$. The received parameters weren't subject of the investigation of normal distribution law by KolmogorovSmirnov test. Therefore the statistical significance of intergroup difference was estimated by Mann-Whitney test and nonparametric Kruskal-Wallis test. It was applied Spearman's rank correlation coefficient. The difference was considered statistically significant at level $p<0,05$. It was applied the dispersive analysis of parameters of heart rate variability before and after the physical activity of the maximum aerobic power.

\section{Results}

Performed researches demonstrated that at rest female volleyball players have heterogeneity of different types of cardio-hemo-dynamic. The following types of cardio-hemo-dynamic were determined according to the typological analysis: in $7(38,9 \%)$ female volleyball players - hypodynamic; in 6 female volleyball players $(33,3 \%)$ - eukinetic; in 5 female volleyball players $(27,8 \%)$ hyperkinetic.

The significantly higher parameters of heart rate, the heart index, stroke and minute volume of blood and rate pressure product $(\mathrm{p}<0,05)$ were determined in female volleyball players with the hyperkinetic type of cardiohemo-dynamic. The female volleyball players with the hypodynamic type of cardio-hemo-dynamic had lowest start values. In female volleyball players with the eukinetic type of cardio-hemo-dynamic these parameters were in the interposition.

It is determined that in female volleyball players with the hyperkinetic type of cardio-hemo-dynamic essential increase in systolic blood pressure reaches a maximum until the end of the first minute of physical activity of the maximum aerobic power. In female volleyball players with the hypodynamic and eukinetic type of cardiohemo-dynamic, the systolic blood pressure reached a maximum in the second minute of physical activity. Further, it practically doesn't change until the end of the 
test. Increase in systolic blood pressure during physical activity performing of the maximum aerobic power realized due to increase in stroke volume. It didn't depend on the cardio-hemo-dynamic type. In female volleyball players with the hypodynamic type of cardio-hemodynamic, the heart index increased in 2,82 times. In female volleyball players with the hyperkinetic type of cardio-hemo-dynamic, the heart index increased in 3,09 times $(\mathrm{p}<0,05)$.

In all female volleyball players the parameter of average arterial blood pressure is essentially changed after the first minute of physical activity of the maximum aerobic power. It occurs due to increase in heart rate and a statistically significant decrease of parameter of the rate pressure product $(\mathrm{p}<0,05)$.

In female volleyball players with the eukinetic type of cardio-hemo-dynamic the tendency to normalization of all cardio-hemo-dynamic parameters appeared in the first minute of the recovery period. In female volleyball players with the hypodynamic and hyperkinetic type of cardio-hemo-dynamic the significance of differences is kept until the end of the fifth minute of rest.

After physical activity of the maximum aerobic power all female volleyball players have statistically significant increase in the hematocrit and level of hemoglobin $(\mathrm{P}<0,05)$. In hypodynamic type of cardio-hemo-dynamic the increase in the hematocrit and level of hemoglobin comes against the background of increase in number of erythrocytes. It is observed decrease of erythrocytes quantity in female volleyball players with eukinetic type of cardio-hemo-dynamic. In female volleyball players with hyperkinetic type of cardio-hemo-dynamic physical activity of the maximum aerobic power is caused by increase in quantity of erythrocytes in the largest volume (on average in $15,3 \pm 0,11 \%, \mathrm{p}<0,05$ ).

It was determined contents of adenosine triphosphate (ATP) decrease and concentration of adenosine monophosphate (AMP) increase in female volleyball players (tab. 1).
The most expressed changes of the studied parameters are registered in female volleyball players with the hyperkinetic type of cardio-hemo-dynamic. Confirmation of this is changes of spectral parameters in female volleyball players with a different type of cardio-hemodynamic. It is determined that in female volleyball players with hyperkinetic type of cardio-hemo-dynamic the majority of spectral and hour parameters of heart rate variability significantly differed from similar parameters of volleyball players from eukinetic and hypodynamic type of cardio-hemo-dynamic (tab. 2, 3).

Calculation of nonparametric Spearman correlation coefficient results demonstrate that there is a significantly positive connection between separate parameters of heart rate variability and value of the erythrocytes deformation index (see tab. 3, a mark *).

It is observed restructuring of erythrocytes near these changes. In female volleyball players with eukinetic type of cardio-hemo-dynamic after the physical activity of the maximum aerobic power, erythrocytes are left almost without changes (fig. 1A). In female volleyball players with the hypodynamic type of cardio-hemo-dynamic (fig. 1B) have reversibly changed forms of erythrocytes. In the hyperkinetic type of cardio-hemo-dynamic: it is observed an increase of irreversibly changed forms in $15,0 \%$; the ability of erythrocytes' aggregation increased $(p<0,05)$. It is evident as an increase in the amount of "adhesion threads" between separate cells (fig. 1C).

Results of the macroelements analysis argue for the increase in erythrocytes deformation in female volleyball players with hyperkinetic type of cardio-hemo-dynamic (fig. 1). Contents of calcium and magnesium at these female volleyball players were respectively in $11,6 \%$ but $36,9 \%$ more, than in female volleyball players with eukinetic type of cardio-hemo-dynamic and respectively in $23,7 \%$ and $45,6 \%$ more, than in female volleyball players with hypodynamic type of cardio-hemo-dynamic.

Table 1. The contents of adenylic nucleotides in erythrocytes of peripheral blood in female volleyball players with different type of hemo-dynamic $(M \pm S D)$

\begin{tabular}{llll}
\hline Parameter & $\begin{array}{l}\text { Hypodynamic type of } \\
\text { cardio-hemo-dynamic } \\
(\mathbf{n}=6)\end{array}$ & $\begin{array}{l}\text { Eukinetic type of cardio- } \\
\text { hemo-dynamic }(\mathbf{n}=7)\end{array}$ & $\begin{array}{l}\text { Hyperkinetic type of } \\
\text { cardio-hemo-dynamic } \\
(\mathbf{n}=5)\end{array}$ \\
\hline ATP, mmol/L & $1,46 \pm 0,18^{\#}$ & $1,87 \pm 0,14$ & $1,12 \pm 0,33^{* \#}$ \\
ADP, $\mathrm{mmol} / \mathrm{L}$ & $0,68 \pm 0,34^{\#}$ & $1,17 \pm 0,36$ & $0,79 \pm 0,42^{\#}$ \\
AMP, mmol/L & $1,4 \pm 0,45^{\#}$ & $0,89 \pm 0,12$ & $1,68 \pm 0,63^{\#}$ \\
ATP/ADP & $2,22 \pm 0,46^{\#}$ & $1,62 \pm 0,23$ & $1,62 \pm 0,91^{*}$ \\
ADP $\times$ AMP/ATP & $0,74 \pm 0,61^{\#}$ & $0,56 \pm 0,11$ & $1,31 \pm 1,07^{* \#}$ \\
\hline
\end{tabular}

Notes: ATP - adenosine triphosphate; AMP - adenosine monophosphate; ${ }^{*}$ - the statistical significance of the difference in parameters in comparison with female volleyball players with the hypodynamic type of cardio-hemodynamic \# - in comparison with parameters of female volleyball players with eukinetic type of cardio-hemo-dynamic $(p<0,05)$. 
Table 2. Value of heart rate variability parameters of female volleyball players with a different type of blood circulation and value of erythrocytes deformation index before the physical activity of the maximum aerobic productivity ( $M \pm S D$, $\mathrm{n}=18$ )

\begin{tabular}{llll}
\hline & \multicolumn{2}{l}{ Type of blood circulation regulation / erythrocytes deformation index level } \\
Parameter & hypotonic / low & eukinetic / low & $\begin{array}{l}\text { / average } \\
\text { hypodynamic }\end{array}$ \\
\hline HR, bpm & $78,1 \pm 1,53$ & $71,9 \pm 1,43$ & $70,6 \pm 1,94$ \\
Average mean of RR- & $0,78 \pm 0,04$ & $0,85 \pm 0,03$ & $0,88 \pm 0,02$ \\
interval, ms & $0,05 \pm 0,001$ & $0,06 \pm 0,002$ & $0,06 \pm 0,006$ \\
SDNN, ms & $0,05 \pm 0,003$ & $0,05 \pm 0,001$ & $0,06 \pm 0,012$ \\
RMSSD, ms & $27,1 \pm 4,57$ & $30,1 \pm 1,87$ & $31,7 \pm 7,11$ \\
pNN50, \% & $4003,1 \pm 305,33^{*}$ & $4427,3 \pm 247,19$ & $5414,9 \pm 1281,6^{*}$ \\
TF, ms ${ }^{2}$ & $1093,9 \pm 54,31^{*}$ & $1610,5 \pm 81,63$ & $1902,8 \pm 58,32^{*}$ \\
VLF, ms ${ }^{2}$ & $1103,3 \pm 47,85^{*}$ & $1345,5 \pm 92,74$ & $1744,8 \pm 52,44^{*}$ \\
LF, ms ${ }^{2}$ & $1194,2 \pm 66,14^{*}$ & $1081,9 \pm 101,32$ & $1089,4 \pm 427,08$ \\
$H F, m s^{2}$ & $1,4 \pm 0,12^{*}$ & $1,7 \pm 0,15$ & $2,4 \pm 0,42^{*}$ \\
LF/HF & $50,7 \pm 1,35^{*}$ & $57,4 \pm 1,42$ & $64,4 \pm 4,32^{*}$ \\
pLF, \% & $49,2 \pm 1,04^{*}$ & $42,6 \pm 1,02$ & $35,7 \pm 4,33^{*}$ \\
\hline pHF, \% & & & \\
\hline
\end{tabular}

Notes: $1 .{ }^{*}$ - in comparison with female volleyball players with eukinetic type of cardio-hemo-dynamic the difference is significant at $p<0,05 ; 2$. HR - heart rate; LF - spectrum power in the low frequency range; HF - spectrum power in the high frequency range; RMSSD - mean-square residual between duration of R-R intervals; SDNN - a mean square standard deviation of R-R intervals; SDANN -standard deviation of a difference between consecutive R-R intervals; PNN50 - a part of consequent R-R intervals difference between which exceeds $50 \mathrm{~ms}$; TF -general power of spectrum; VLF - spectrum power in the range of very low frequencies.

Table 3. Value of parameters of heart rate variability of female volleyball players with a different type of blood circulation and value of erythrocytes deformation index after the physical activity of the maximum aerobic productivity ( $M \pm S D$, $\mathrm{n}=18$ )

\begin{tabular}{|c|c|c|c|}
\hline \multirow[b]{2}{*}{ Parameter } & \multicolumn{3}{|c|}{ Type of blood circulation regulation / erythrocytes deformation index level } \\
\hline & hypotonic / low & eukinetic / low & $\begin{array}{l}\text { hypodynamic } \\
\text { / average }\end{array}$ \\
\hline $\mathrm{HR}, \mathrm{bpm}$ & $90,8 \pm 3,06^{*}$ & $82,6 \pm 0,92$ & $78,1 \pm 3,43$ \\
\hline $\begin{array}{l}\text { Average mean of RR- } \\
\text { interval, ms }\end{array}$ & $0,68 \pm 0,04 *$ & $0,74 \pm 0,02$ & $0,78 \pm 0,04$ \\
\hline SDNN, ms & $0,05 \pm 0,001$ & $0,05 \pm 0,001$ & $0,05 \pm 0,001$ \\
\hline RMSSD, ms & $0,03 \pm 0,001^{*}$ & $0,04 \pm 0,001$ & $0,05 \pm 0,001^{*}$ \\
\hline pNN50, \% & $18,7 \pm 5,53^{*}$ & $16,9 \pm 1,43$ & $20,0 \pm 5,94^{*}$ \\
\hline $\mathrm{TF}, \mathrm{ms}^{2}$ & $2208,1 \pm 374,33^{*}$ & $3447,8 \pm 292,12$ & $5282,6 \pm 117,24^{*}$ \\
\hline $\mathrm{VLF}, \mathrm{ms}^{2}$ & $689,1 \pm 105,47^{*}$ & $1298,5 \pm 181,63$ & $1975,3 \pm 157,75^{*}$ \\
\hline $\mathrm{LF}, \mathrm{ms}^{2}$ & $581,2 \pm 92,12 *$ & $1112,9 \pm 77,51$ & $1660,6 \pm 297,82^{*}$ \\
\hline $\mathrm{HF}, \mathrm{ms}^{2}$ & $588,8 \pm 142,64$ & $649,0 \pm 66,33$ & $1017,3 \pm 313,15^{*}$ \\
\hline $\mathrm{LF} / \mathrm{HF}$ & $1,8 \pm 0,32 *$ & $2,0 \pm 0,11$ & $2,8 \pm 0,22$ \\
\hline $\mathrm{pLF}, \%$ & $48,6 \pm 4,44^{*}$ & $62,9 \pm 1,53$ & $65,6 \pm 5,44$ \\
\hline $\mathrm{pHF}, \%$ & $51,4 \pm 4,42^{*}$ & $37,1 \pm 1,57$ & $34,5 \pm 5,23$ \\
\hline
\end{tabular}

Note. see notes to tab. 2 . 


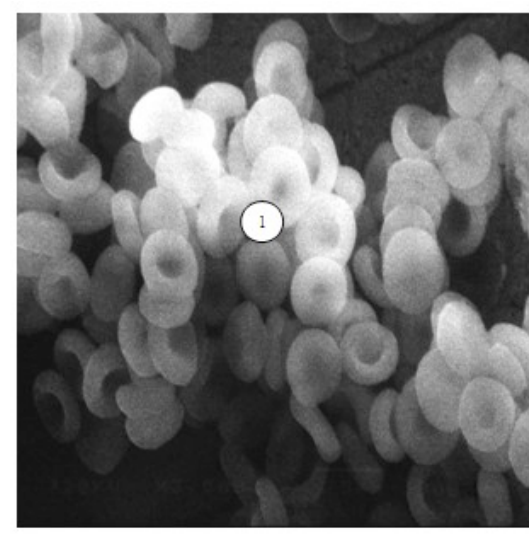

A

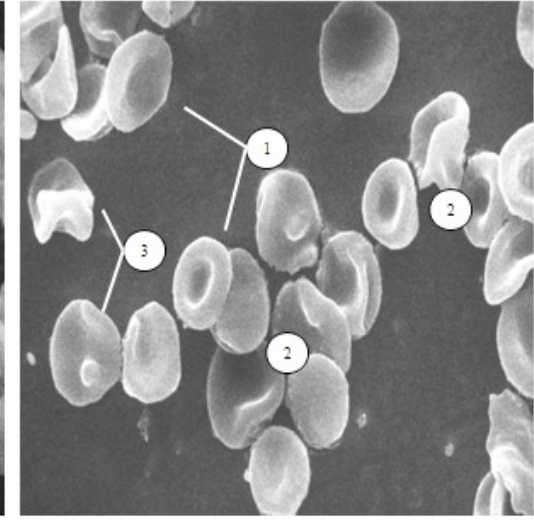

B

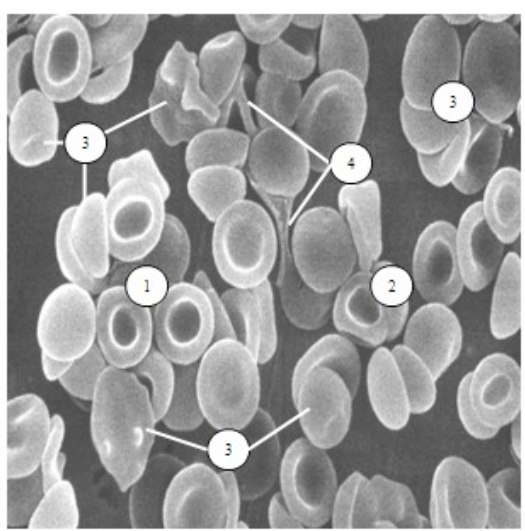

C

Fig. 1. Restructuring of erythrocytes of peripheral blood of female volleyball players with eukinetic, hypodynamic and hyperkinetic types of hemo-dynamic after the physical activity of the maximum aerobic power: 1 - normal forms of erythrocytes, 2 - reversibly changed forms of erythrocytes, 3 - irreversibly changed forms of erythrocytes, 4 "adhesion threads". The scanning electronic microscopy. Fig. $1 \mathrm{~A}$ is increased in 1200 times; fig. $1 \mathrm{~B}$ and fig. $1 \mathrm{C}$ are increased in 1500 times.

\section{Discussion}

It is known that different morphofunctional parameters are actively applied in estimating of adaptation potential of a human body. These parameters are integrate and informative in planning training process and predicting the level of physical fitness of athletes [21].

Recognized parameters of the influence of positive and negative factors are the index of functional systems tension and parameters of heart rate variability [10]. However many aspects of this problem remain insufficiently studied. In particular, the hemo-cardioregulation system provides close interrelation between a contour of vegetative regulation and organs of the cardiorespiratory system. It also demands consideration of erythrocytes condition [13]. In scientific literature, we haven't found data concerning studying such interrelation; changes of these components of hemo-cardioregulation system in physical activity of different power.

Aerobic physical activities of different level of intensity play a significant role in the formation of the general endurance of an organism. It is especially important during competitions of female volleyball players [21]. It integrates a large number of processes occurring in the different levels: from cellular and to a complete organism [10]. The leading role in researches of endurance belongs to the determination of factors which promote activization of power exchange and the vegetative systems of its providing: cardiorespiratory and humoral. At the same time, the researches of cellular reactions in physical activity in the course of training which connected with the increase in the general endurance of an organism of female volleyball players remain out of sight are neglected $[22,23]$.

Erythrocytes are convenient objects for such researches. Erythrocytes take part in the processes connected with homeostasis maintenance at the level of the whole organism [7, 10, 24]. These cells could take part in the regulation of an acid-base balance, water and electrolytic to balance, microrheological blood state. They also connect amino acids, lipids, and toxins. All this is of direct interest in the development of the general endurance of athletes' organism [25].

It is defined that in $57 \%$ of female volleyball players with hyperkinetic type of cardio-hemo-dynamic there are negative morphological changes of erythrocytes. It is caused by biochemical violations and intracellular 

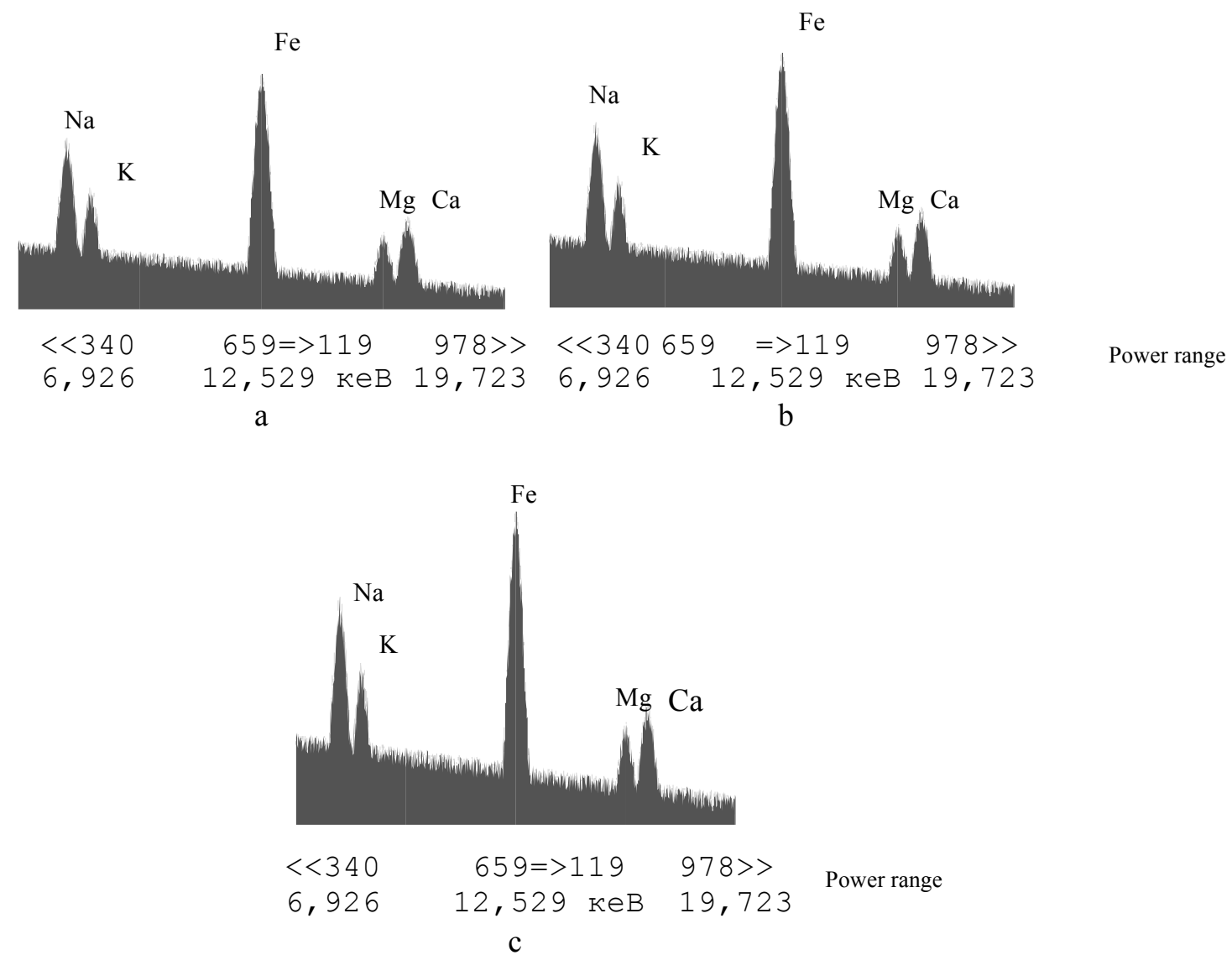

Fig. 2 The histogram of macroelements contents distribution in erythrocytes in female volleyball players with hypodynamic, eukinetic and hyperkinetic cardio-hemo-dynamic types.

prevalence of concentration of magnesium [11] and calcium [26] ions. The obtained data demonstrate that at rest to female volleyball players with hyperkinetic type of cardio-hemo-dynamic higher requirements to the power supply of heart activity. It can be explained by the prevalence of parameters of systolic blood pressure at them. It is followed by increase in need of myocardial oxygen requirement [27].

Female volleyball players with hypodynamic and eukinetic type of cardio-hemo-dynamic performed by more economical heart work. The proof is that they have the highest absolute values of heart work parameters: the waste energy for movement of one liter of minute volume of blood; capacities of left ventricle contraction and stroke volume output.

It is known that the human organism of with different type of blood circulation reacts to physical activity of the maximum aerobic power by the increase in heart index $[5,10,13,28]$. In a comparison of heart index values was traced the tendency to increase of its values from hypodynamic blood circulation to hyperkinetic type. Female volleyball players with hyperkinetic type of cardio-hemo-dynamic had the highest parameters of heart index. Under such circumstances, there are violations of the structural integrity of erythrocytes. It promotes their intravascular lysis and could lead to the development of anemia [29]. The existence of these changes has a negative impact on the level of somatic health and sports effectiveness of female volleyball players. It demands the corresponding correction of the training process and timely application of adequate actions which are directed to the elimination of development of possible pathological changes in an organism of female volleyball players.

The performed research demonstrated that cardioregulation depends on typological features of human's erythrocytes: deformability and intracellular concentration of macroelements.

\section{Conclusions}

It is observed close correlation interrelation $(\mathrm{r}=0,83)$ between the type of cardio-hemo-dynamic and biochemical parameters of blood which defines a certain type of erythrocytes deformation and their increased ability to aggregation. Therefore the quantitative definition of back and not back changed forms of erythrocytes of peripheral blood could have practical value: control of a condition of athletes' organism in the training process.

\section{Conflict of interests}

The authors declare that they have no conflict of interest. 


\section{References}

1. Korkushko OV. Methods of the analysis and age standards of heart rate variability. Kiev: Health; 2008. (in Russian)

2. Lisovs'kij B. Functional reserves of cardiorespiratory system as parametre of person's health. Visnik Prikarpats'kogo universitetu, 2006;2:31-34. (in Ukrainian)

3. Dovganik MS, Chichkan OA, Strel'chenko VV, Iavors'kij OG. Changes in the cardiovascular system of men and women for long jogging sessions. Slobozhans'kij naukovosportivnij visnik, 2014;2:76-79. (in Ukrainian)

4. Jagiello W, Jagiello M, Kalina RM, Barczynski BJ, Litwiniuk A, Klimczak J. Properties of body composition of female representatives of the Polish national fencing team - the sabre event. Biology of Sport. 2017;34(4):401-406. doi:10.5114/ biolsport.2017.70526

5. Mikhajlov VM. Stress testing under control of the ECG. Ivanovo: publishing house IGMI; 2005. (in Russian)

6. Barker D, Wallhead T, Quennerstedt M. Student learning through interaction in physical education. European Physical Education Review. 2016;4: 1-6. doi:10.1177/1356336x16640235

7. Jensen FB. The dual roles of red blood cells in tissue oxygen delivery: oxygen carriers and regulators of local blood flow. Journal of Experimental Biology. 2009;212(21): 3387-93. doi:10.1242/jeb.023697

8. Tan Y, Sun D, Wang J, Huang W. Mechanical characterization of human red blood cells under different osmotic conditions by robotic manipulation with optical tweezers. IEEE Transactions on Biomedical Engineering. 2010;57(7): 181625. doi:10.1109/tbme.2010.2042448

9. Lorente-Catalan E, Kirk D. Student teachers understanding and application of assessment for learning during a physical education teacher education course. European Physical Education Review. 2015;22(1): 65-81. doi:10.1177/1356336x15590352

10.Mikhaylova LA. Central hemodynamics indices in senior pupils with increased educational and motive loading. Siberian Medical Review. 2013;3,55-8. doi:10.20333/250001362013-3-55-58

11. Brock SJ, Rovegno I, Oliver KL. The influence of student status on student interactions and experiences during a sport education unit. Physical Education \& Sport Pedagogy. 2009;14(4): 355-75. doi:10.1080/17408980802400494

12.Malikov MV, Bogdanovs'ka NV, Svat'iev AV. Functional diagnostics in physical training and sport. Zaporozhye: ZNU; 2006. (in Ukrainian)

13.Romanenko VA. Diagnostics of functional abilities of a human body. Donetsk: Publ., DNU; 2005. (in Russian)

14.Bergamini C, Gambetti S, Dondi A, Cervellati C. Oxygen, Reactive Oxygen Species and Tissue Damage. Current Pharmaceutical Design. 2004;10(14): 1611-26. doi:10.2174/13816120433846 64

15.Svat'iev AV, Malikov MV. Functional diagnostics in physical training and sport. Zaporozhye: ZSU;, 2004. (in Ukrainian)
16.Bianchini K, Wright PA. Hypoxia delays hematopoaesis: retention of embryonic hemoglobin and erythrocytes in larval rainbow trout, Oncorhynchus mykiss, during chronic hypoxia exposure. Journal of Experimental Biology. 2013;216(23): 4415-25. doi:10.1242/jeb.083337

17.Fuks AI, Elderer J, Ellemunter H. Cardiology clearance index: Normal values, repeatability, and reproducibility in Cardiology system-healthy children. Pediatric Cardiology, 2010;43(12): 1180-85.

18. Mytckan B, Popel' S, Vipasniak I. Morpho-functional changes in the oxygen-transport system of students at the testing of cardiorespespiration stability. Health, Sport, Rehabilitation, 2017;3(4):41-47. doi:10.5281/zenodo.1136083

19. Valbonesi M, Garelli S, Montani F, Cefis M, Florio G. A simple and rapid test for the quantification of osmotic fragility of red blood cells. Acta Haematologica. 2009;69(2): 106-10. doi:10.1159/000206863

20.Popel' SL, Mitckan BM, Lapkovskiy EI. Mechanism of changing adaptation potential and morpho-biochemical parameters of erythrocytes in students with different mode of day after physical load. Regulatory Mechanisms in Biosystems. 2017;8(2): 124-34. doi:10.15421/021711

21.Lambert MI. General Adaptations-Exercise: Acute Versus Chronic and Strength Versus Endurance Training. Exercise and Human Reproduction. New York, London: Heidelberg Dordrecht; 2016. doi:10.1007/978-1-4939-3402-7 6

22.Kang M. Should the physical educator be held accountable for student physical activity levels beyond physical education? Physical Education, Recreation \& Dance. 2016;87(6): 5556. doi:10.1080/07303084.2016.1192930

23.Koumantakis GA, Watson PJ, Oldham J. A. Supplementation of general endurance exercise with stabilisation training versus general exercise only. Clinical Biomechanics.2005;20(5), 474-82. doi:10.1016/j.clinbiomech.2004.12.006

24.Mairbäurl H. Red blood cells in sports: effects of exercise and training on oxygen supply by red blood cells. Frontiers in Physiology. 2013;4: 34-36._doi:10.3389/fphys.2013.00332

25.Mohanty JG, Nagababu E, Rifkind JM. Red blood cell oxidative stress impairs oxygen delivery and induces red blood cell aging. Frontiers in Physiology. 2014;5: 1-5. doi:10.3389/fphys.2014.00084

26.Chang Y, Bo B. Effects of exhaustive exercise on the ATPsensitive potassium channel of rat cardiac sinoatrial node. Journal of Science and Medicine in Sport. 2015;19: 65. doi:10.1016/j.jsams.2015.12.159

27.Sassen B, Cornelissen VA, Kiers H. Physical fitness matters more than physical activity in controlling cardiovascular disease risk factors. European Journal of Cardiovascular Prevention \& Rehabilitation. 2009;16(6): 677-83.

28.Soares-Miranda L, Sandercock G, Valente Y. Vigorous physical activity and vagal modulation in young adults. European Journal of Cardiovascular Prevention \& Rehabilitation. 2009;16(6): 705-11.

29.Matarrese P. Peroxynitrite induces senescence and apoptosis of red blood cells through the activation of aspartyl and cysteinyl proteases. FASEB Journal. 2005;19(3): 416-18. doi:10.1096/fj.04-2450fje 
Information about the authors:

Mytskan B.M.; http://orcid.org/0000-0002-5853-713X; bogomdan_21@mail.ru; Department of Theory and Methodology of Physical Culture and Sports, Vasyl Stefanyk Precarpathian National University; 57 Shevchenko Str., Ivano-Frankivsk, 76018, Ukraine.

Verbovyi V. P.; http://orcid.org/0000-0002-5004-4170; verbovuyif@ukr.net; Department of Tactical-Special, Physical and Fire Training, National Academy of Internal Affairs; 3 The National Guard str., Ivano-Frankivsk, 76018, Ukraine.

Chovhan R. Ya.; http://orcid.org/0000-0003-4168-1773; rostikchovhan@gmail.com; Department of Physical Culture, Vasyl Stefanyk Precarpathian National University; 57 Shevchenko Str., Ivano-Frankivsk, 76018, Ukraine.

Zemska N.O.; http://orcid.org/0000-0002-8169-9954; zemskanadia@gmail.com; Department of Sport-Pedagogical Subject Matters, Vasyl Stefanyk Precarpathian National University; 57 Shevchenko Str., Ivano-Frankivsk, 76018, Ukraine.

Kryzanivskaya O. F.; http://orcid.org/0000-0003-4934-3840; ksenija6791@6791gmail.com; Department of Physical Culture, Vasyl Stefanyk Precarpathian National University; 57 Shevchenko Str., Ivano-Frankivsk, 76018, Ukraine.

Bublyk S.A.; http://orcid.org/0000-0002-9666-2038; bublyk1979@ukr.net; Department of Physical Culture, Vasyl Stefanyk Precarpathian National University; 57 Shevchenko Str., Ivano-Frankivsk, 76018, Ukraine.

Mocherniuk V. B.; http://orcid.org/0000-0001-5821-3357; mocher.n@gmail.com; Department of Theory and Methodology of Physical Culture and Sports, Vasyl Stefanyk Precarpathian National University; 57 Shevchenko Str., Ivano-Frankivsk, 76018, Ukraine.

Faichak R. I.; http://orcid.org/0000-0001-9082-1213; romfay@meta.ua; Department of Physical Culture, Vasyl Stefanyk Precarpathian National University; 57 Shevchenko Str., Ivano-Frankivsk, 76018, Ukraine.

Pjatnichuk G.O.; http://orcid.org/0000-0001-6328-4168; halinapy@gmail.com; Department of Sport-Pedagogical Subject Matters, Vasyl Stefanyk Precarpathian National University; 57 Shevchenko Str., Ivano-Frankivsk, 76018, Ukraine.

Popel' S. L. (Corresponding author); http://orcid.org/0000-0002-2161-535X; popelsergij@gmail.com; Department of Theory and Methodology of Physical Culture and Sports, Vasyl Stefanyk Precarpathian National University; 57 Shevchenko Str., Ivano-Frankivsk, 76018, Ukraine.

Baskevich O. V.; http://orcid0000-0001-5118-061X; hejlion@gmail.com; Department of Physical Rehabilitation, Vasyl Stefanyk Precarpathian National University; 57 Shevchenko Str., Ivano-Frankivsk, 76018, Ukraine.

Cite this article as: Mytckan BM, Verbovyi VP, Chovhan RYa, Zemska NO, Kryzanivskaya OF, Bublyk SA, Mocherniuk VB, Faichak RI, Pjatnichuk GO, Popel' SL, Baskevich OV. Influence of physical activity of the maximum aerobic power on hemodynamic and morpho-biochemical of change of erythrocytes of female volleyball players. Pedagogics, psychology, medicalbiological problems of physical training and sports, 2018;22(5):272-279. doi:10.15561/18189172.2018.0508

The electronic version of this article is the complete one and can be found online at: http://www.sportpedagogy.org.ua/index.php/PPS/issue/archive

This is an Open Access article distributed under the terms of the Creative Commons Attribution License, which permits unrestricted use, distribution, and reproduction in any medium, provided the original work is properly cited (http://creativecommons.org/licenses/by/4.0/deed.en).

Received: 02.02.2018

Accepted: 06.03.2018; Published: 30.09.2018 